\title{
Aesthetic Education in China: Problems and Solutions
}

\author{
Wang Jun \\ School of Philosophy, Wuhan University
}

*Corresponding Author: Wang Jun, School of Philosophy, Wuhan University

\begin{abstract}
The pure theory of aesthetics is philosophical. However, when aesthetics faces the reality, one of its vital functions will be aesthetic education. Aesthetic education is the education of man's technique, desire and wisdom. It is applied to cultivate sound personalities and to carry forward the humanistic spirit. It is part of man's complete education and an important way of man's self-fulfillment. In contemporary China, there overflow three main problems which are nihilism, technicalism and hedonism. People have a tendency to lose faith, become slaves to technology, and pursue material things excessively. Under these circumstances, aesthetic education needs to perform its mission in the three aspects which are talent strategy, personality building and the re-construction of the humanistic spirit. Only in this way will aesthetic education be able to help to promote the rebuilding, purifying and formation of man's personality, regain man's nature, and help to promote the construction of the social economy, culture, politics and a harmonious society for a more beautiful future through the three transformation which are from techniques to art, from desire to love and from knowledge to wisdom.
\end{abstract}

Keywords: aesthetic education, contemporary China, problems, mission

\section{INTRODUCTION}

Aesthetic education is the implementation of aesthetic theory in the aesthetic daily activities and the creation of beauty. Its purpose is to help people establish correct aesthetic points of view, cultivate healthy aesthetic taste and noble aesthetic ideals, train the ability of feeling beauty and creating beauty, and finally promote the development of beauty and art.

In the Zhou Dynasty (before 1046 - the first 256 years) of China, there were six classical arts (ceremony, music, shooting, driving carriages, book learning, and mathematics) in the aesthetic education in the human-shaping education system. During China's long history of humanistic education, aesthetic education played a critical role. At the beginning of the twentieth century, China's educator Cai Yuanpei put forward the slogan "Aesthetic Education on Behalf of the Religion", advocating cultivating people's sentiments, cultivate people's nobility and fine habits through aesthetic education.

In the western countries, for example, in the ancient Greek there were muse education and sport in the education system which were about aesthetic education. During the medieval times, the use of religious art such as architecture, sculpture, painting and music was aesthetic education for people. While in the early modern times, the Renaissance humanism advocated the cultivation of complete and perfect personality, so the education subjects included the aesthetic education as well. And the eighteenth-century French thinker Rousseau argued for natural education instead of rational coercion. He emphasizes the role of sensation, especially sensory, visual and auditory sensation. And the eighteenth-century German philosopher Schiller's aesthetic education was of epoch-making 
significance. (Peng 2005, 132) Schiller's “On the Aesthetic Education of Man" for the first time clearly put forward the concept of aesthetic education, clarifying a systematic description of the problem of aesthetic education. Schiller believed that a person who transferred from a natural person to a moral person must turn into an aesthetic person. Aesthetics is the solution of the opposition and conflict of sensibility and reason, and is the comprehensive and harmonious development and liberation of human nature. He also regards aesthetic education as a powerful means of cultivating new people and transforming society. In the modern times philosophers such as Heidegger criticized the forgetting of human nature caused by the framework of technology and put forward the aesthetic thought of the fourfold plays of the heaven, earth, mortals and gods, in which the fourfolds are independent and yet function in a harmonious unity. Heidegger learned from Holderlin's poem “...poetically man dwells on this earth...." (Heidegger 1999, 213) and expressed his expectation of a glorious future.

Therefore, if the metaphysical attention of aesthetics mainly involves theoretical problems, then when aesthetics faces the reality, it will carry out the mission of aesthetic education. When we speak of aesthetic education in China, we mean that there exist some outstanding and urgent problems, and aesthetic education can effectively promote the solution to these problems because of its own nature.

\section{Problems}

In the contemporary world, with the rapid development of science and technology, the world economy presents a trend of globalization, informationization and high speed, and people face the plight of a world of material appreciation and the devaluation of humanity. In China, it is no exaggeration to say that the pursuit of material things is now far more important than everything else in the process of modernization and the economic construction which are the center of the Chinese journey to a better future. During the journey, the technology modernization and the diversification of desire and pleasure provide the best means of satisfaction, while it will lead to people's boredom and sense of nothingness whether people's desire is satisfied or not. In a much more serious situation, people lose faith and spiritual pillars. The society is full of nihilism, technicalism and hedonism (Peng 2006, 1).

The first problem is nihilism. It is manifested in many aspects, such as the abandonment of the traditional Chinese spiritual values. Confucianism in the Chinese history once became the spiritual pillar of the Chinese people, but since the beginning of the early modern times it began to decline. China turned anti-traditional, for people threw away the essence of the tradition alongside its dross. Another aspect is of the blind worship of western ideas. Since the reform and opening-up policy began to be carried out, a large number of western ideas have been introduced to China. On the one hand, some of the good ideas have played a role; on the other, some bad ideas also had a great impact. (Zhong) At the beginning of the twentieth century, in the face of national conditions, Cai Yuanpei linked the aesthetic education with the fate of the country and put forward the slogan of "Aesthetic Education on Behalf of the Religion". It was a slogan with a strong spirit at that time. The role of aesthetic education is mainly to cultivate people's spirit in life, to meet people's metaphysical need. In the period of the absence of universal religious belief in China then, aesthetic education could play the role of replacing religion. There is no doubt that in the contemporary China of nihilism prevailing, the publicity of the universality of the aesthetic education and its transcendence will be the new need of the new era.

The next problem is technicalism. "People tend to regard technology as a means of responding to their own desires, so they are very obsessed with technology. Actually, technology is nothing but a tool, but it is regarded by many as something above all like that the omnipotence of God. Hence, people 
replaced the pursuit of spirit with the worship of technology." (Zhong) Technology brings the greatest possibility to mankind and opens up a way for the realization of human freedom. However, on the other hand, when technology invents new ways of actions, it is bound to neglect and forget even more possibilities. For example, "in Heidegger's view, as a challenging show, the premise and foundation of the modern technology is 'to set'. The so-called 'to set' is to look at things in certain directions and judge them whether they are useful or not. This kind of attitude will be about the challenge of nature, which will result in a variety of things in their unnatural state of showing...." (Zhang 2003, 4) Modern technology is becoming the ruling power in people's life. The dominance of science and technology especially directly affects people's lives, changes the ways of how people live, and shakes people's values. Science and technology should essentially be people-oriented and have their limitation, but in reality it has crossed its own boundaries and has become a framework and began to set everything. People are being alienated by technology and become slaves to science and technology. In this sense, science and technology have become the yoke which restricts the free and comprehensive development of humans.

The third problem is hedonism. In the industrial society, the industrial civilization often maintains and expands the production through the stimulation of consumption which leads consumers in the direction to worship goods. People caught in the alienation of consumption cannot recognize their real need and will become a consumer machine. The thoroughgoing pursuit of material consumption will inevitably result in leading to the development of the deformity of society as a whole - a high degree of material civilization and a relatively low spiritual state $(\mathrm{Hu} 2002,11)$. The modern information society also leads to an excessive pursuit of material enjoyment, leading to the prevalence of social hedonism. In modern China, the power of money to dominate the society is too great and it is enough to distort the values of truth and goodness, making people fall into slaves of the false, the bad and the ugly instead of the true, the good and the beautiful. This is a materialistic society. And aesthetic education becomes more and more significant only because it is a desperate society. Aesthetic education is an essential and important part in cultivating human values. The education of values is an issue that should be a matter of ethical education. The current task for aesthetic education to assist the moral education is to reverse China's overly heavy hedonism.

Therefore, in the contemporary China, which is full of these three problems, it is necessary to advocate aesthetic education in the areas of ideal education, humanistic spirit education and moral education, to transform the hearts, to purify the mind, to create a sound personality, to carry forward the humanistic spirit of the Chinese nation, and to make it a conscious action of the whole society.

\section{SOLUTIONS}

In the face of all the above problems, aesthetic education should reshape in the three aspects, the talent strategy, personality construction and humanistic spirit, to perform its specific mission. That is to say, aesthetic education is to promote the transformation of hearts, the purification of minds, and the construction of a beautiful society through promoting the social economic construction, cultural construction, political construction and the construction of a harmonious society. In this way, aesthetic education helps to make a change for humans: to turn technology to art, to turn desire to love, and to turn knowledge to wisdom.

\subsection{To Overcome Technicalism Through Talent Strategy}

As a talent, one must first be a person, and his or her skills come second. But for a long time, we emphasize more on skills rather than on the personality itself and the personnel training is embarked on the road of technicalism-pursuing quick success to cultivate talents and training talents persuing quick success, which lead to the prevalence of social technology. In contrast, the implementation of 
new talent strategy can overcome technicalism. And aesthetic education can promote the overcoming of technicalism in the way of turning technology to art.

The new century is a century of more intense competition. The competition of the world in the aspects of political, economic, military, science and technology and others are finally due to the competition of talents. And the key talent is firstly the man. Man as a living being between heaven and the earth, he is firstly equal to the rest of other beings and secondly he is not the same for he is a unique living being. The difference between man and other beings lies in that man is the caregiver and guardian of the others. As in the relationship between man and technology, man will regard technology as technology. He will neither abandon technology nor worship it at the far end. In the cultivation of talent, in addition to the intellectual education such as technical education, there should be more emphasis on moral education, aesthetic education, etc.. In addition to professional training, there should be emphasizing on the overall quality of man as well. In technical education, people master technology for the service for themselves, not vice versa, so that they do not rely on technology or turn slaves to technology.

In this way, to implement the strategy of strengthening the country through talent and to overcome the technicalism, personnel training model should go beyond the contradiction between technology and humanities and cherish the pursuit of a humanistic integration of science and technology to make it an organic one. In the contemporary times of the prevalence of technicalism, the scientific and technological trends are still running in the way of embezzling education, which calls for emotional and rational combination through aesthetic education so that people become persons of whole and sound personality. What is more, it is of vital importance that aesthetic education should be carried out at all levels of education, run through the whole process of education and accompany people's growth process of all education. As Confucius said, "Poetry makes a man, courtesy develops a man, and music fully matures a man". The aesthetic education here runs through the whole process of human education. And the three aspects, making a man, developing a man and fully maturing a man happen not only diachronically but also synchronically. That means, the three aspects will happen simultaneously. Only in this way, can aesthetic education cultivate new talent with ideals, morality, quality and finally skills. This kind of talent strategy can make man become true man, make technology function as technology, and determine the relationship between people and technology so as to overcome technicalism.

\subsection{To Overcome Hedonism Through Personality Construction}

The contemporary China enjoy a highly developed material civilization, while at the same time it experiences the loss of spiritual civilization which is manifested as personality vacancies. And because of the lack of faith, people are driven into the crazy pursuit of material things. Due to the pursuit and the squeeze of the material things, people turned to decadence and many of them are filled with void and turn into one dimensional. Still, the social system is characterized with imperfect problems and give rise to numbers of people who are in the habit of pursuing material desires, power, carnal desire for the purpose of hedonistic characters. Therefore, it is an important task that may not be ignored to promote personality construction and to overcome hedonism through aesthetic education.

In the west, the shaping of personality is mainly done through religion. However, there is no such idea as God in the west. The spirit of the Chinese people is often a mixture of religious, moral and artistic experience. And such kinds of experience are often expressed in the form of artistic or aesthetic experience. (Peng 2005, 32) In China, the purpose of aesthetic education is to create a healthy personality, and comparatively role of aesthetic education in Chinese culture is more important. In Chinese tradition, it is believed that the highest personality must reach a free and transcendent realm, 
and the experience of aesthetic education which is similar to that of religious feelings can achieve such a freedom and transcendence.

The people are the social people, while the society is a human society, so the self-improvement and the social perfection are consistent. Aesthetic education is to promote the self-improvement and the social perfection, so that the self and the society will return to their nature. When people and things return to their own nature, it will be the same as the existence of the personality as expressed in history. Confucius said, "I will tolerate those who misunderstand me." (Zhu 1983, 47) Mencius said, "No fortune shall corrupt my soul. No poverty shall dampen my will. And no power shall suppress my pride." (Zhu 1983, 266) Heidegger also describe in the same similar way of "Letting be" or "Releasement" (Heidegger 1990). As such, aesthetic education is the most original meaning of education. It is the integrity of the human education. It can effectively promote the personality construction, and will cultivate people who want to love. The point here is not only to overcome the certain desires, but also reach the pure emotions and become free beyond the daily chaos and emotions. Therefore, a person who turns from desire to love is a man who overcomes hedonism and is a man who ascends to a noble realm..

\subsection{To Reshape the Humanistic Spirit to Overcome Nihilism}

In one of the traditional Chinese classics "The Book of Changes", it reads, "The best of all civilization is humanity spirit." (Tang 1995, 58) This is to say, people should behave themselves according to the development of human society formed by the traditional culture such as ethics, morality, judgments, systems, etc. to regulate their action and to construct a harmonious society. The formation of humanistic spirit should be people-oriented, reveal the meaning of human existence, and embody the dignity and value of human beings. It should be the cultural spirit pursuing human free and comprehensive development. For nihilism, it can be overcome through the remodeling of humanistic spirit, and aesthetic education can also fulfill its functions in this respect.

Heidegger once divided the basic history of philosophy and his own modern ideology, that is, in the ancient Greece it is about surprise, in the medieval times it is about faith, in the early modern times it is about doubt, and in the modern times it is mainly about boring. Being bored is about the experience of nothingness. In our modern civilized society, with the operation of economic life and the accompanying wealth of life, people often have two opposing feelings, that is, anxiety and boredom. People's understanding of the meaning of life is entirely subject to the reality of the material desire, and they have no faith in comprehending the profound and ture meaning of life. In this case, aesthetic education is facing a challenge. Aesthetic education should first liberate people's personality and spirit from the life of materiality, so that people realize that the most meaningful life is not about the state of depression of chatting, curiosity or ambiguity. Aesthetics should also help to overcome the sinking of life generated by anxiety and boredom as mentioned above. It should help people to form noble aesthetic ideals and pursue the spiritual realm and the true meaning of life (Yuan 2001, 1).

In order to rebuild the humanistic spirit to overcome nihilism, there is an urgent need to rebuild the faith. In Chinese history, the great characters are those who are personality models of faith. And in the traditional aesthetic education, this belief and faith in personality and aesthetic education was embodied in the "mind-rectifying, self-cultivating, family-regulating, state-ordering, and finally the ideal land-governing" of the Confucian book "The Great Learing" (Zhu 1983, 3). In the "The Book of Changes", it is also full of images of persons who are of great and gorgeous personalities because of their belief and faith in the truth (Tang 1995). Therefore, we may rebuild the faith to overcome nihilism, inheriting all the excellent cultural heritage of Chinese and western history. The values and methods of the spiritual home built by traditional aesthetic education can become the spiritual pillars 
of the contemporary Chinese people. In all, we should truly realize the people-oriented education and rebuild the humanistic spirit through the aesthetic education, so that people's emotional impulses and rational impulses combine to achieve the game impulse in free activities, so that man become truly free man, and finally wise man. The true wisdom of wisdom about life is the wisdom of Being. Only with the wisdom of Being, will people know how to live and will nihilism be able to be overcome.

\section{CONClusion}

Contemporary society is in a world of nihilism, technologism and hedonism, and contemporary China is an unskilled and even more dangerous one. Therefore, aesthetic education in contemporary China is about to take part in its own mission. In a word, aesthetic education should play a role in the promotion of talent strategy, and talents should be the talent of all-round development. Aesthetic education should play a role in the task of cultivating and perfecting the personality, because the perfect perfection of the personality is the guarantee of the free person, and also directly the guarantee of talents. And aesthetic education should take part in its mission in the reconstruction of the humanistic spirit of the Chinese nation, because the humanistic spirit is directly related to the national survival, the prosperity of the country and the construction of a harmonious society. Contemporary China calls for the return of aesthetic education and the strengthening of aesthetic education to overcome nihilism, technologism and hedonism. The mission of aesthetic education in contemporary China will be a significant driving force to promote advanced culture, improve the quality of the whole people and build a harmonious society.

\section{ACKNOWLEDGEMENTS}

The paper is supported by "The Fund of China Scholarship Council" (CSC No. 201306275005) and "The Fundamental Research Funds for the Central Universities" (No. 20110330) of China.

\section{REFERENCES}

[1] Hu, Jinfeng. "Review of Consuming Rresearch." Philosophical Trends 11 (2002).

[2] Heidegger, Martin. Gelassenheit. Neske: Pfullingen, 1990.

[3] Martin, Heidegger. Poetry, Language, Thought. Beijing: China Social Sciences Publishing House, 1999.

[4] Peng, Fuchun. Introduction to Philosophical Aesthetics. Beijing: People's Publishing House, 2005.

[5] Peng, Fuchun. "Philosophy and the Contemporary Problems". Xinhua Abstracts 1 (2006).

[6] Tang, Mingbang. Commentary and Anatation on the Book of Changes. Beijing: Zhonghua Book Company, 1995.

[7] Yuan Jixi. "Aesthetic Education and Personality Concern." National Art 1 (2001).

[8] Zhu, Xi. A Variorum of the Four Confucian Books. Beijing: Zhonghua Book Company, 1983.

[9] Zhong, Xin. Representative Peng Fuchun's Proposal of Implementation of the 'Spirit Project in the Whole Society'. Http://politics.people.com.cn/GB/14562/3232467.html.

[10] Zhang, Xiangen. "Science, Art and Truth: A Study of Heidegger's Thought of Truth." Science and Technology Dialectics 4 (2003).

Citation: Wang Jun. "Aesthetic Education in China: Problems and Solutions." International Journal of Humanities Social Sciences and Education (IJHSSE), vol 4, no. 12, 2017, pp. 134-139. doi: http://dx.doi.org/10.20431/2349-0381.0412017.

Copyright: () 2017 Authors. This is an open-access article distributed under the terms of the Creative Commons Attribution License, which permits unrestricted use, distribution, and reproduction in any medium, provided the original author and source are credited. 